\title{
Obstructive sleep apnoea and open heart surgery: a review of its incidence and impact to patients
}

\author{
Sivakumar Krishnasamy ${ }^{1}$, Saidah Mohd Sahid ${ }^{2}$, Shahrul Amry Hashim ${ }^{1}$, Sukcharanjit Singh ${ }^{3}$, \\ Frances Chung ${ }^{4}$, Raja Amin Raja Mokhtar ${ }^{1}$, Wang Chew Yin ${ }^{5}$ \\ ${ }^{1}$ Cardiothoracic Unit, University of Malaya Medical Centre, Kuala Lumpur, Malaysia; ${ }^{2}$ Department of General Surgery, Hospital Sultanah Bahiyah, \\ Alor Setar, Kedah, Malaysia; ${ }^{3}$ Department of Anaesthesiology, Griffith Base Hospital, Griffith, New South Wales, Australia; ${ }^{4}$ Department of \\ Anaesthesia, University Health Network-Toronto Western Hospital, Toronto, Canada; ${ }^{5}$ Department of Anaesthesiology, University Malaya Medical \\ Centre, Kuala Lumpur, Malaysia \\ Contributions: (I) Conception and design: S Krishnasamy, WC Yin, F Chung; (II) Administrative support: RA Mokhtar, SA Hashim; (III) Provision \\ of study materials or patients: S Krishnasamy, SM Sahid, SA Hashim, S Singh, RA Mokhtar; (IV) Collection and assembly of data: S Krishnasamy, \\ SM Sahid; (V) Data analysis and interpretation: S Krishnasamy, SM Sahid, WC Yin; (VI) Manuscript writing: All authors; (VII) Final approval of \\ manuscript: All authors. \\ Correspondence to: Dr. Sivakumar Krishnasamy. Cardiothoracic Surgery, Department of General Surgery, Faculty of Medicine, University Malaya, \\ Jalan University, 50603 Kuala Lumpur, Malaysia. Email: sivaprotoss77@yahoo.com.
}

Background: Obstructive sleep apnea (OSA) is a serious health disorder which contributes to cardiovascular complications, decreased work productivity, automobile accidents, and death. This condition is characterized by a temporary cessation of breathing resulting due to upper airway closure during a person's sleep. Strain to the heart caused by this repetitive hypoxic insult can lead to postoperative complications for patients undergoing heart surgery. Recognizing cardiac surgical patients with OSA is important. Early recognition and intervention such as use of BiPAP device can reduce the postoperative complications due to OSA.

Methods: The aim of this study is to identify the incidence of unrecognized OSA in cardiac surgical patients. This is a retrospective analysis of a prospective data of the study which was done between July 2012 and July 2013 in University Malaya Medical Center. All patients undergoing elective cardiac surgery were recruited and the demographic data, questionnaire and the portable sleep study results were obtained. Patients were followed up till 30 days to record any complications. Data were entered in SPSS version 17 and analysis was done.

Results: The incidence of OSA was $61.4 \%$ and $43.5 \%$ were moderate to severe OSA. There was male predominance of OSA (79\%) with a mean age of 60 years. OSA subjects had shorter inter-incisor distance $(4.18 \pm 0.6 \mathrm{~cm})$ and larger waistline $(94.1 \pm 12.1 \mathrm{~cm})$. The STOP-Bang questionnaire has a sensitivity of $75.8 \%$ in predicting apnoa-hypopnea index $(\mathrm{AHI}) \geq 5$ /hour.

Conclusions: OSA can be diagnosed with a simple screening questionnaire and a bedside portable sleep study. Cardiac patients diagnosed with OSA can be pre-emptively given extra attention in managing their postoperative care.

Keywords: Obstructive sleep apnea (OSA); open heart surgery; STOP-Bang; ApneaLink

Submitted May 02, 2019. Accepted for publication Nov 05, 2019.

doi: $10.21037 /$ jtd.2019.11.44

View this article at: http://dx.doi.org/10.21037/jtd.2019.11.44

(c) Journal of Thoracic Disease. All rights reserved. 


\section{Introduction}

Obstructive sleep apnea (OSA) is a disorder where there is cessation of breathing during sleep that occurs repetitively due to the complete or partial pharyngeal obstruction and the reduced pharyngeal muscle tone during sleep, particularly in obese individuals (1). OSA has both health and social implication. It can lead to excessive daytime sleepiness, cognitive dysfunction, and reduce work performance. Studies also suggest that OSA may contribute to the development of systemic hypertension (2), cardiovascular disease (3), and abnormalities in glucose metabolism (4). A strong association between OSA and coronary artery disease (CAD) has been shown (5).

Recognising OSA in surgical patients preoperatively can reduce the problems related to OSA. Appropriately timing the extubation or preparing respiratory support with continuous positive airway pressure (CPAP) post extubation has helped to reduce the postoperative complications related to OSA (6). Postoperative complications of OSA can also be reduced with the administration of non-opioid analgesia in the postoperative period (7).

Patients can be screened for OSA by using a screening tool in the form of questionnaire such as the STOP Questionnaire (S: snore loudly, T: daytime tiredness, O: observed to stop breathing during sleep, P: high blood pressure). A modified form of this questionnaire includes BMI, age, neck circumference and gender (STOP-Bang Questionnaire). Polysomnography (PSG) remains the gold standard in diagnosing OSA, but it is costly and requires trained personnel to operate. Besides questionnaires, a portable sleep monitoring device, ApneaLink (ResMed, San Diego), which records nasal pressure, thoracic excursion, body position, pulse oximetry and heart rate can be used as a diagnostic tool. The device can be applied to patients to collect the overnight data (Figures 1 and 2).

Apnea is defined as the complete cessation of airflow for at least 10 seconds. There are three types of apneas to be scored: obstructive, central and mixed. In OSA, respiratory effort is maintained but ventilation decreases or disappears because of partial or total occlusion in the upper airway. Central sleep apnea is defined as reduced respiratory effort resulting in reduced or absent ventilation, usually seen in patients with heart failure. Mixed apnea is often characterized by starting with central apneas and ending with obstructive events, these events are thought to be pathophysiologically related to obstructive apneas and are considered to be part of the obstructive sleep apnea hypopnea syndrome (OSAHS). A hypopnea is defined as a reduction in airflow (30-50\%) that is followed by an arousal from sleep or a decrease in oxyhemoglobin saturation $(3-4 \%)(8,9)$.

The gold standard diagnostic test for OSA is overnight laboratory PSG, which is deemed inconvenient, not cost effective and requires trained personnel to apply the sophisticated equipment that involves multi-channel polygraph recordings. It requires a sleep laboratory with extensive facilities with full time overnight skilled technician.

Due to the expensive and long waiting list for overnight sleep study, a more practical and low cost method of diagnosing OSA involves both screening questionnaire and portable sleep monitoring device that can narrow down numbers of subjects that warrants sleep study based on the clinical prediction scoring and unattended device that can be applied at the comfort of own home.

There a few screening tools used to screen for high risk of OSA including the widely used STOP/STOPBang questionnaires, Berlin Questionnaire, Wisconsin questionnaire, the Sleep Disorder Questionnaire (SDQ) and Hawaii sleep questionnaire. The Berlin Questionnaire is a commonly used screening tool in primary care that consists of 11 questions of 3 categories, including the quality of snoring, daytime tiredness and co morbidities. However, going through 11 questions maybe time consuming for anaesthetists or surgeons. A simple and concise STOP-Bang questionnaire consists of 8 questions which are snoring, tiredness, observed stopped breathing during sleep, pressure, BMI, age older than 50, neck circumference $>40 \mathrm{~cm}$ and gender male. A score of 3 or greater ( 1 for each yes) is considered positive and high risk for OSA (10). The diagnostic ability of this questionnaire has a sensitivity of $93 \%$.

According to the American Academy of Sleep Medicine (AASM) (11) the diagnosis of OSA is confirmed if the number of obstructive events (apneas, hypopneas + respiratory event related arousals) on PSG is $\geq 15$ events/ hour in the absence of associated symptoms or $\geq 5 /$ hour in a patient who reports any of the following: unintentional sleep episodes during wakefulness; daytime sleepiness; unrefreshing sleep; fatigue; insomnia; waking up breath holding, gasping or choking; or the bed partner describing loud snoring, breathing interruptions, or both during the patient's sleep.

The frequency of obstructive events is reported as an 


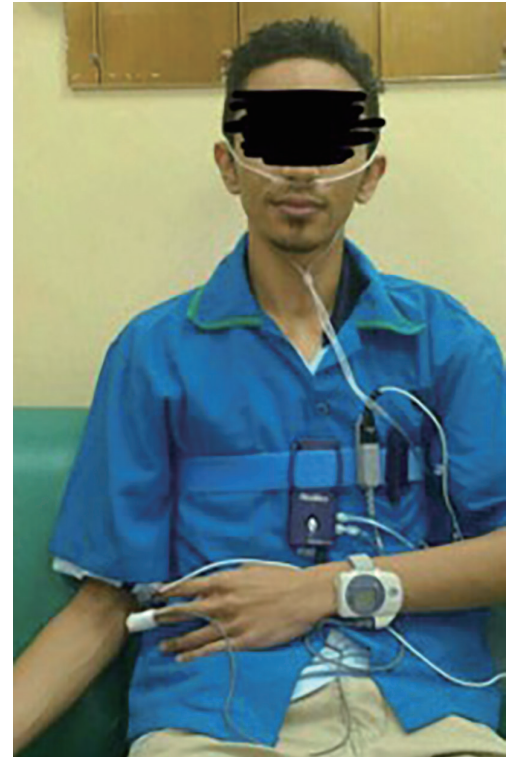

Figure 1 Apnealink being placed on our patient on the night before surgery.

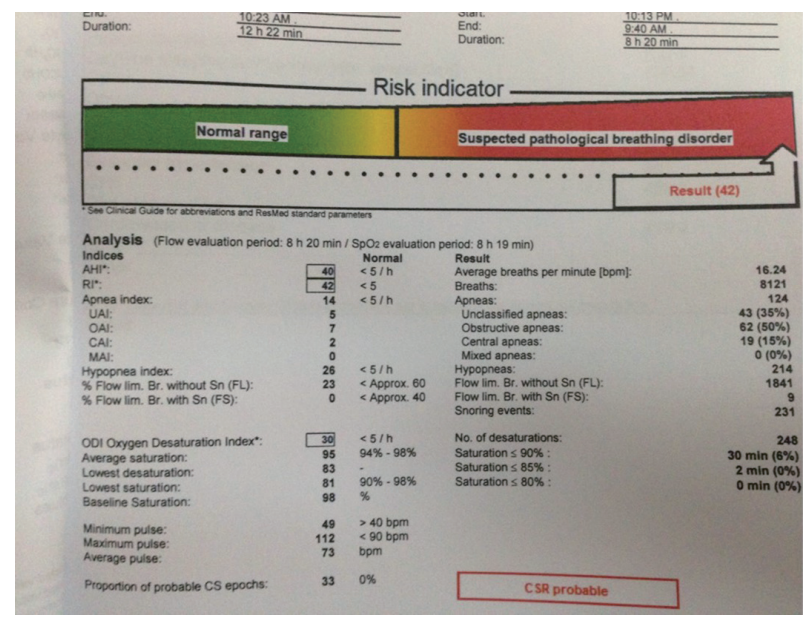

Figure 2 Printed report from the Apnealink device which is used for the data collection.

apnea-hypopnea index (AHI).

The severity of OSA is defined as mild for AHI $\geq 5 / \mathrm{hr}$ and $<15 / \mathrm{hr}$; moderate for AHI $\geq 15 / \mathrm{hr}$ and $\leq 30 / \mathrm{hr}$; and severe for $\mathrm{AHI}>30 / \mathrm{hr}$.

\section{Methods}

The aim of this study is to determine the incidence of OSA in patients undergoing cardiac surgery at University Malaya
Medical Centre (UMMC). The primary end point is the prevalence of OSA. The secondary end points are: (I) postoperative complications in patients with or without OSA; and (II) predictive factors associated with OSA. This is a prospective study of a retrospective data of patients who had undergone open heart surgery in UMMC from $1^{\text {st }}$ July 2012 till $30^{\text {th }}$ May 2013. Medical ethics clearance obtained from University Malaya Medical Center Medical Ethics Board. Subjects were recruited when they were admitted to the ward for their elective open heart surgery. The inclusion criteria consisted of all stable patients scheduled for elective open heart surgery.

The exclusion criteria:

(I) They have a previous diagnosis of OSA or any sleep-related breathing disorder.

(II) They are unwilling or physically unable to use the portable PSG on the night before surgery.

(III) Use of oxygen therapy during the night of the sleep study.

(IV) Use of medications that could affect sleep.

(V) Presence of any serious respiratory or cardiac medical conditions that the investigator should decide as unsafe to participate in the study.

All the data were recorded in a booklet and this include all the pre-operative, intraoperative, postoperative monitoring, risk assessment questionnaires: STOP-Bang and Epworth sleepiness scale, and the portable sleep monitor. The portables sleep monitor is easy to use (Figure 1) and the printed data is easy to interpret (Figure 2). Subjects were followed for 30 days post-surgery. Results were recorded in SPSS version 18 and analysed to compare differences between the two groups.

\section{Results}

Between $1^{\text {st }}$ July 2012 and $30^{\text {th }}$ May 2013, 118 participants were recruited, out of which 17 patients were excluded due to: 5 (4\%) due to cancellation of surgery, $1(0.8 \%)$ was given oxygen supplement the night of sleep study, $1(0.8 \%)$ had insufficient sleep time (less than 2 hours), 2 (1.7\%) had their surgeries done thoracoscopically, and $8(6.7 \%)$ had technical problem with the sleep studies. Thus 101 subjects completed the sleep study and were used for the analysis.

The demographics data of the 101 patients are shown in Table 1. The mean age of patients was $60 \pm 3.1$ years. Seventy-three of the study population were male and $27.7 \%$ were female. The majority of the patients were in the age group of 56-65 years old (35.6\%), followed by those above 
Table 1 Patient demographic with AHI and STOP BANG score

\begin{tabular}{|c|c|c|}
\hline \multirow{2}{*}{ Patient demographic } & \multicolumn{2}{|c|}{ No. of patients } \\
\hline & $\mathrm{N}=101$ & Percentage \\
\hline \multicolumn{3}{|l|}{ Gender } \\
\hline Male & 73 & $72.3 \%$ \\
\hline Female & 28 & $27.7 \%$ \\
\hline \multicolumn{3}{|l|}{ Age } \\
\hline$<45$ & 7 & $6.9 \%$ \\
\hline $46-55$ & 26 & $25.7 \%$ \\
\hline $56-65$ & 36 & $35.6 \%$ \\
\hline$>66$ & 32 & $31.7 \%$ \\
\hline \multicolumn{3}{|l|}{ Ethnicity } \\
\hline Malay & 35 & $34.7 \%$ \\
\hline Chinese & 41 & $40.6 \%$ \\
\hline Indian & 25 & $24.8 \%$ \\
\hline \multicolumn{3}{|l|}{ BMI } \\
\hline <18.4 (underweight) & 2 & $2.0 \%$ \\
\hline 18.5-22.9 (normal) & 26 & $25.7 \%$ \\
\hline 23.0-27.4 (pre obese) & 48 & $47.5 \%$ \\
\hline 27.5-34.9 (class I obese) & 23 & $22.8 \%$ \\
\hline 35.0-39.9 (class II obese) & 1 & $1.0 \%$ \\
\hline$>40$ (class III obese) & 1 & $1.0 \%$ \\
\hline \multicolumn{3}{|l|}{ ASA } \\
\hline > Mild systemic disease (II) & 93 & $92.1 \%$ \\
\hline > Severe systemic disease (III) & 8 & $7.9 \%$ \\
\hline \multicolumn{3}{|l|}{ History of smoking } \\
\hline Yes & 46 & $45.5 \%$ \\
\hline No & 55 & $54.5 \%$ \\
\hline \multicolumn{3}{|l|}{ Surgery } \\
\hline CABG & 88 & $87.1 \%$ \\
\hline Valve replacement & 8 & $7.9 \%$ \\
\hline Both & 5 & $5.0 \%$ \\
\hline \multicolumn{3}{|l|}{$\mathrm{AHI}$} \\
\hline No OSA $(<5)$ & 39 & $38.6 \%$ \\
\hline OSA ( $\geq 5)$ & 62 & $61.4 \%$ \\
\hline \multicolumn{3}{|l|}{$\mathrm{AHI}$} \\
\hline No OSA $(\mathrm{AHI}<5)$ & 39 & $38.6 \%$ \\
\hline
\end{tabular}

Table 1 (continued)
Table 1 (continued)

\begin{tabular}{lcc}
\hline \multirow{2}{*}{ Patient demographic } & \multicolumn{2}{c}{ No. of patients } \\
\cline { 2 - 3 } & $\mathrm{N}=101$ & Percentage \\
\hline Mild OSA AHI $(\geq 5$ and $>15)$ & 35 & $56.5 \%$ \\
Moderate OSA (AHI $\geq 15$ and $<30)$ & 13 & $21.0 \%$ \\
Severe OSA (AHI $\geq 30)$ & 14 & $22.5 \%$ \\
STOP BANG score & & \\
Low risk (<3) & 30 & $29.7 \%$ \\
High risk (3 and above) & 71 & $70.3 \%$ \\
Epworth risk scoring & & \\
Low risk (10 and below) & 95 & $94.1 \%$ \\
High risk (>10) & 6 & $5.9 \%$ \\
\hline
\end{tabular}

$\mathrm{AHI}$, apnea-hypopnea index; CABG, coronary artery bypass graft; OSA, obstructive sleep apnea.

66 years old (31.7\%), 46-55 years old $(25.7 \%)$ and $6.9 \%$ below 45 years old. Among the patients, $40.6 \%$ of the study population are Chinese, followed by Malays (34.7\%) and Indians (24.8\%).

Almost $50 \%$ of the study population are in pre obese group (BMI $23.0-27.4 \mathrm{~kg} / \mathrm{m}^{2}$ ), followed by normal $\left(18.5-22.9 \mathrm{~kg} / \mathrm{m}^{2}\right)$ BMI group $(25.7 \%)$, and obese $\left(27.5-34.9 \mathrm{kgm}^{2}\right)$ about $22.8 \%$. Two patients had BMI $>35 \mathrm{~kg} / \mathrm{m}^{2}$ and 2 were underweight (BMI $<18.4 \mathrm{~kg} / \mathrm{m}^{2}$ ). Almost half (45.5\%) of the study population had history of smoking. Eighty-seven percent of the patients had coronary artery bypass graft surgery (CABG), $8 \%$ open valve replacement surgery and $5 \%$ a combined procedure. And, 92.1\% were ASA status II and 7.9\% were ASA status III.

Based on the portable sleep studies applied the night before surgery, about $61.4 \%$ of the patients were diagnosed with OSA with $56.5 \%$ mild, $21.0 \%$ moderate and $22.5 \%$ severe OSA.

When compared between patients with and without OSA, both have similar mean age, height, BMI, neck circumference and Mallampati score. There is difference in the waistline where the OSA group has higher mean waistline than the non OSA group $(94.1 \pm 12.2$ vs. $90.7 \pm 9.6 \mathrm{~cm})$. The mean thyromental distance is shorter in the OSA group $(7.73 \pm 0.9 \mathrm{~cm})$ compared to non OSA group $(7.9 \pm 1.0 \mathrm{~cm})$. The mean inter incisor distance also is shorter in the OSA group $(4.18 \pm 0.6 \mathrm{~cm})$ as compared to non OSA group $(5.5 \pm 6.5 \mathrm{~cm})$.

There is difference in the waistline, the thyromental 
distance and intercisior distance between the OSA and nonOSA group.

The mean score for STOP-Bang questionnaire in the non OSA (3.0) and the OSA (3.4) group are similar, whereas the mean score for Epworth risk score is higher in the Non OSA group (3.3) compared to OSA group (1.0). Both the risk scoring questionnaires do not show any significant difference in both Non OSA and OSA group. However, the STOP-BANG questionnaire is higher in the OSA group (75.8\%).

More patients in the OSA group had complications in terms of ICU readmission (3/62), post-operative ventilator support (7/62), death (3/62), non fatal cardiac arrest (1/62), stroke (1/62), pneumonia (3/62), delirium (1/62) and other adverse events (4/62) namely chest re-open within 24 hours [2], left lung collapse [1], anastomosis bleed [1] and hemodynamically unstable for closure [1]. However, the complications are not significant $(\mathrm{P}$ value $>0.05)$.

The correlation between the complications and presence of OSA are tested with Pearson correlation coefficient $\left(r^{2}\right)$ but none of them were significant $(<1.0)$.

The post-operative ventilatory support in OSA group (7/62) is $10 \%$ higher than the non OSA group (4/39) (with odds ratio 1.11). There was no pulmonary embolism or deep vein thrombosis in either group. No difference in the length of ICU stay and hospital stay occurred between the OSA and non OSA group.

In a subsequent analysis, the mild OSA group is the highest with $56.5 \%$ followed by severe OSA group (22.6\%) and moderate OSA group (20.9\%). There is significant difference in ethnicity between the different OSA severity groups (P value 0.034). Age, smoking history, BMI and ASA classification did not show any significant difference between the different severities of OSA.

The post-operative complications among the mild, moderate and severe OSA groups did not show any significant difference. There were no pulmonary embolism, deep vein thrombosis occurred in the OSA group.

Tables 1-6 further illustrate our results.

\section{Discussion}

In this study, we evaluated the prevalence of OSA in patients undergoing open heart surgery by using the STOP-Bang questionnaire and a portable study device, ApneaLink (ResMed, San Diego) which was applied to the patients in the hospital before surgery. The prevalence of OSA was $61 \%$ with mild $56.5 \%$, moderate $21.0 \%$ and severe $22.5 \%$
OSA. Among the OSA group, $43.5 \%$ were moderate to severe OSA.

Our findings are similar to another Brazil study that found $87 \%$ of patients referred for coronary artery bypass graft had OSA and 54\% were moderate to severe OSA (12). Their prevalence of OSA patients is higher due to higher BMI.

In our study, the percentage of new onset atrial fibrillation was unexpectedly higher in the non OSA group $(7,17.9 \%)$ than the OSA group (7, 11.2\%). An atrial tissue gene was found in patients with OSA and the gene expression is less in OSA patients that led to development of atrial fibrillation. This could be due to the recurrent hypoxaemia episodes that downregulate the atrial cardiomyocytes (13). Repetitive hypoxemic events also induce inflammatory cytokines productions causing endothelial dysfunction and heart remodelling $(14,15)$.

We found patients with OSA had higher incidence of pneumonia ( $4.8 \%$ vs. 0$)$, post-operative ventilatory support (11.2 \% vs. $10.0 \%$ ) and ICU readmission (1.6\% vs. 0$)$. Previous study (16) also reported higher postoperative respiratory failure rates in patients with OSA. There are only few studies that examined cardiac postoperative complication in OSA subjects (17). Most reported complications other than $\mathrm{AF}$ are myocardial infarction and non AF arrhythmias, and these are all in non-cardiac surgeries (10,18-20).

Vasu et al. found, 11 times higher chances of postoperative complications in high risk group compared to low risk group of patients with OSA (21). In our study, we found the sensitivity and the specificity of the STOP-Bang questionnaire to be $75.81 \%$ (95\% CI: 63.25-85.77\%) and $38.46 \%$ (95\% CI: $23.38-55.38 \%$ ) We found the sensitivity and the specificity of the Epworth sleepiness scale to be $6.45 \%$ (95\% CI: $1.83-15.72 \%$ ) and $94.87 \%$ (95\% CI: 82.64-99.22\%).

From our observation, patients were reserved especially female patients when asked about snoring habits and sleepiness. Patients have difficulties in giving response to the Epworth sleepiness scale that contains 8 situations with 4 grading scales. The STOP-Bang questionnaire was easy to use as it incorporates anthropometric measurements and does not require patients to give grading scale.

Since the early days of overnight sleep laboratory PSG, various medical technology companies have started to produce portable sleep monitors. The waiting list for a laboratory PSG can be as long as 2 years due to limited study slots and requirements of well trained technicians. This has enabled the development of reliable and highly sensitive portable sleep monitors that can be used as an 
Table 2 Demographics of non OSA and OSA group

\begin{tabular}{|c|c|c|c|}
\hline Baseline characteristic & $\mathrm{AHI}<5$ (non OSA) $(\mathrm{n}=39)$ & $\mathrm{AHI} \geq 5(\mathrm{OSA})(\mathrm{n}=62)$ & $P$ value \\
\hline$<45$ & $5(12.8)$ & $2(3.2)$ & \\
\hline $45-55$ & $9(23.1)$ & $17(27.4)$ & \\
\hline $56-65$ & $9(23.1)$ & $27(43.5)$ & \\
\hline Gender & & & 0.056 \\
\hline Male & $24(61.5)$ & $49(79.0)$ & \\
\hline Female & $15(38.5)$ & $13(21.0)$ & \\
\hline Ethnicity & & & 0.942 \\
\hline Indian & $10(25.6)$ & $15(24.2)$ & \\
\hline ASA & & & 0.491 \\
\hline II & $35(89.7)$ & $58(93.5)$ & \\
\hline III & $4(10.3)$ & $4(6.5)$ & \\
\hline \multicolumn{4}{|l|}{ BMI } \\
\hline$<18.4$ (underweight) & $2(5.1)$ & 0 & 0.467 \\
\hline 18.5-22.9 (normal) & $10(25.6)$ & $16(25.8)$ & \\
\hline 23.0-27.4 (pre obese) & $19(48.7)$ & $29(46.8)$ & \\
\hline
\end{tabular}

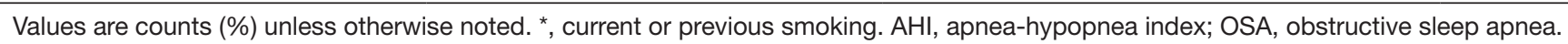

Table 3 Mean baseline characteristic of patients without and with OSA

\begin{tabular}{lcr}
\hline Baseline characteristic & Non OSA group $(\mathrm{n}=39)$ & OSA group $(\mathrm{n}=62)$ \\
\hline Age $($ years), mean \pm SD & $59 \pm 10.8$ & $60 \pm 8.0$ \\
Weight $(\mathrm{kg})$, mean \pm SD & $65.4 \pm 10.9$ & $68.5 \pm 13.1$ \\
Height $(\mathrm{cm})$, mean \pm SD & $161.7 \pm 8.3$ & $162.4 \pm 8.3$ \\
Waistline (cm), mean \pm SD & $90.7 \pm 9.6$ & $94.1 \pm 12.1$ \\
EURO score, mean \pm SD & $2.5 \pm 2.1$ & $1.5 \pm 0.9$ \\
BMI, mean \pm SD & $25.0 \pm 3.9$ & $25.8 \pm 4.3$ \\
Neck circumference $(\mathrm{cm})$, mean \pm SD & $36.5 \pm 3.7$ & $37.2 \pm 3.8$ \\
Mallampati score, mean \pm SD & $1.95 \pm 0.9$ & $1.92 \pm 0.9$ \\
\hline
\end{tabular}

Table 3 (continued) 
Table 3 (continued)

\begin{tabular}{lcc}
\hline Baseline characteristic & Non OSA group $(\mathrm{n}=39)$ & OSA group $(\mathrm{n}=62)$ \\
\hline Thyromental distance $(\mathrm{cm})$, mean \pm SD & $7.9 \pm 1.0$ & $7.73 \pm 0.9$ \\
Inter incisor distance (cm), mean \pm SD & $5.5 \pm 6.5$ & $4.18 \pm 0.6$ \\
Sleep study duration (hours), mean \pm SD & $9.02 \pm 3.26$ & $8.29 \pm 3.26$ \\
AHI, mean \pm SD & $1.3 \pm 1.2$ & $21.0 \pm 16.0$ \\
Oxygen desaturation index, mean \pm SD & $4.0 \pm 12.3$ & $11.2 \pm 13.7$ \\
\hline
\end{tabular}

AHI, apnea-hypopnea index; OSA, obstructive sleep apnea.

Table 4 OSA risk scoring based on risk assessment questionnaire

\begin{tabular}{lcc}
\hline Risk scoring questionnaire & Non OSA group $(n=39)$ & OSA group $(n=62)$ \\
\hline STOP-BANG & & $3.4 \pm 1.3$ \\
Mean \pm SD & $3.0 \pm 1.5$ & $15(24.2)$ \\
Low risk $(<2)$ & $15(38.5)$ & $47(75.8)$ \\
High risk $(\geq 3)$ & $24(61.5)$ & 0.108 \\
Epworth score & & $1.0 \pm 0.2$ \\
Mean \pm SD & $3.3 \pm 3.4$ & $58(93.5)$ \\
Low risk $\leq 10$ & $37(94.9)$ & $4(6.5)$ \\
High risk $>10$ & $2(5.1)$ & 0.784 \\
\hline
\end{tabular}

Values are counts (\%) unless otherwise noted. OSA, obstructive sleep apnea.

Table 5 Complications in OSA and non OSA group

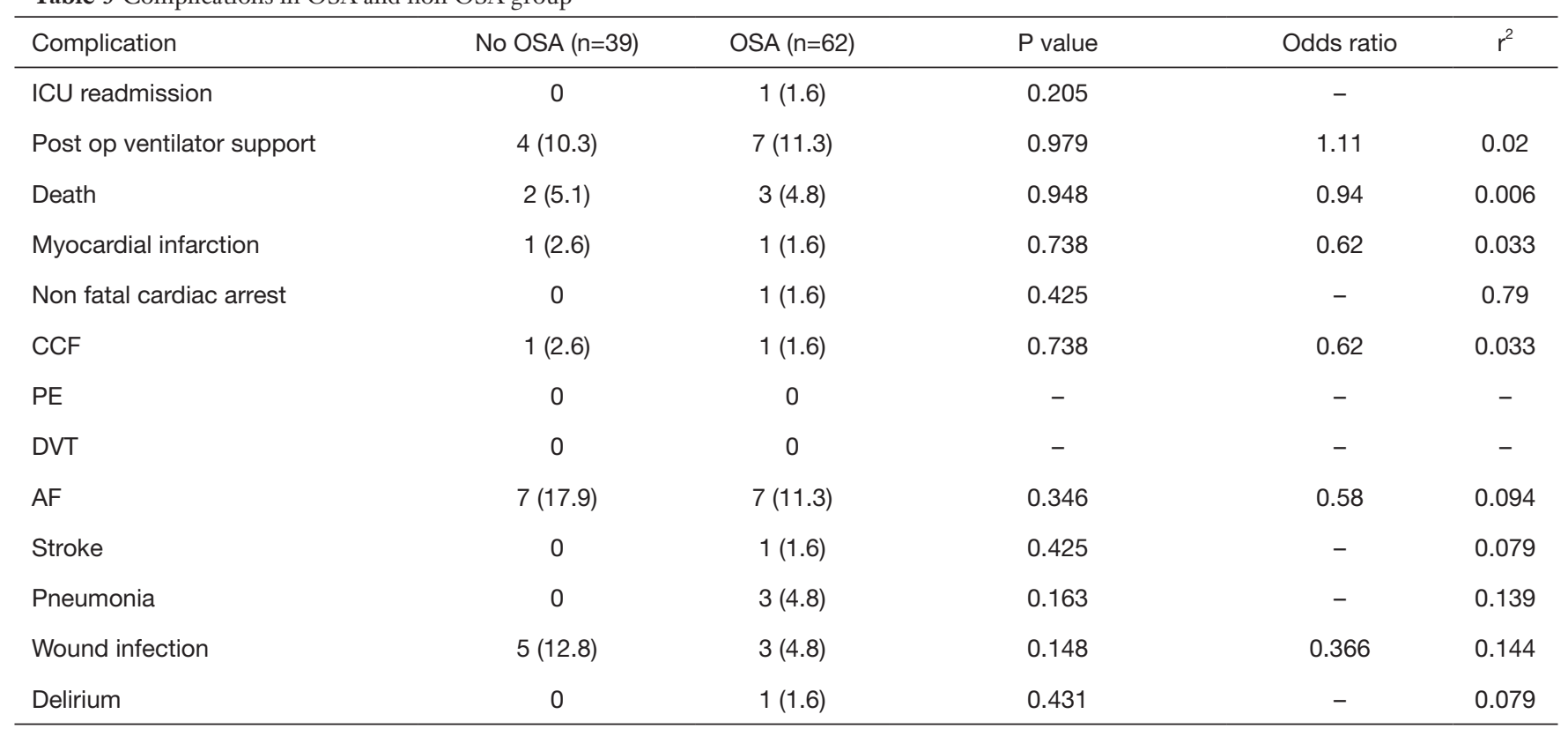

Table 5 (continued) 
Table 5 (continued)

\begin{tabular}{lcccc}
\hline Complication & No OSA $(n=39)$ & OSA $(n=62)$ & P value & Odds ratio $^{2}$ \\
\hline Adverse event & $3(7.7)$ & $4(6.5)$ & 0.801 & 0.81 \\
ICU stay , mean \pm SD & $5.2 \pm 2.6$ & $5.5 \pm 5.1$ & Mann Whitney U 0.512 & 0.25 \\
Hospital stay & $10.7 \pm 5.1$ & $9.3 \pm 5.7$ & Mann Whitney U 0.225 & \\
\hline
\end{tabular}

Values are counts (\%) unless otherwise noted. OSA, obstructive sleep apnea.

Table 6 Baseline characteristic and complications in patients with OSA

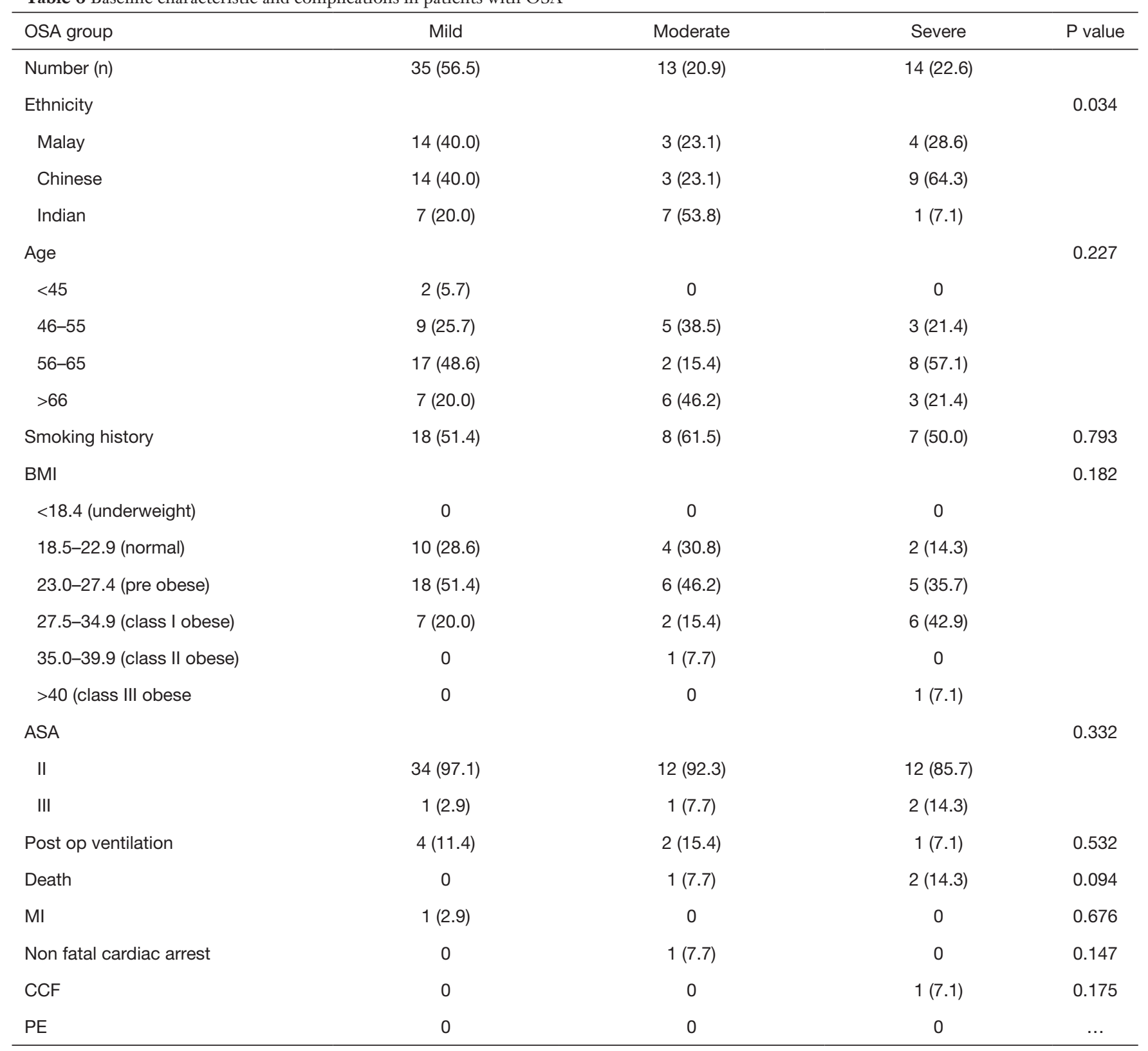

Table 6 (continued) 
Table 6 (continued)

\begin{tabular}{lcccc}
\hline OSA group & Mild & Moderate & Severe & P value \\
\hline DVT & 0 & 0 & 0 & - \\
AF & $5(14.3)$ & 0 & $2(14.3)$ & 0.351 \\
Stroke & $1(2.9)$ & 0 & 0 & 0.676 \\
Pneumonia & $1(2.9)$ & $1(7.7)$ & $1(7.1)$ & 0.708 \\
Wound infection & $3(8.6)$ & 0 & 0 & 0.296 \\
Delirium & $1(2.9)$ & 0 & 0 & 0.676 \\
\hline
\end{tabular}

Values are counts (\%) unless otherwise noted. OSA, obstructive sleep apnea.

alternative to the traditional PSG (22). Previous studies found that home portable monitoring has high sensitivity in detecting OSA compared to in laboratory PSG $(23,24)$.

In our study there was a $1.6 \%$ incidence of stroke and delirium in the OSA. A previous study found an increaserisk of stroke of $1 \%$ for every increment of $\mathrm{AHI}$ (25). A pilot study in assessing the relation of postoperative delirium and OSA in (26) found the incidence of delirium is higher in OSA group $(53 \%$ vs. $20 \%, \mathrm{P}$ value $=0.0123)$.

\section{Conclusions}

As predicted in many of the previous studies, unrecognized OSA can be as high as $61 \%$ in patients undergoing elective open heart surgery. They are associated with higher incidence of postoperative complications that includes respiratory, cardiac and other complications. A simple STOP-Bang questionnaire and portable monitoring device can be used to screen and diagnose OSA when patients are admitted to the ward preoperatively. Cardiac patients diagnosed with OSA can be pre-emptively given extra attention in managing their postoperative care.

\section{Acknowledgments}

Funding: University Malaya Research Grant (Grant number: RG423-12HTM).

\section{Footnote}

Conflicts of Interest: The authors have no conflicts of interest to declare.

Ethical Statement: The authors are accountable for all aspects of the work in ensuring that questions related to the accuracy or integrity of any part of the work are appropriately investigated and resolved. Medical ethics clearance obtained from University Malaya Medical Center Medical Ethics Board.

\section{References}

1. Meoli AL, Casey KR, Clark RW, et al. Clinical Practice Review Committee. Hypopnea in sleep-disordered breathing in adults. Sleep 2001;24:469-70.

2. Punjabi NM. The Epidemiology of Adult Obstructive Sleep Apnea. Proc Am Thorac Soc 2008;5:136-43.

3. Ip MS, Lam B, Lauder IJ, et al. A community study of sleep-disordered breathing in middle-aged Chinese men in Hong Kong. Chest 2001;119:62-9.

4. Ip MS, Lam B, Tang LC, et al. A community study of sleep-disordered breathing in middle-aged Chinese women in Hong Kong: prevalence and gender differences. Chest 2004;125:127-34.

5. Sharma SK, Kumpawat S, Banga A, et al. Prevalence and risk factors of obstructive sleep apnea syndrome in a population of Delhi, India. Chest 2006;130:149-56.

6. Kushida CA, Littner MR, Morgenthaler T, et al. Practice parameters for the indications for polysomnography and related procedures: An update for 2005. Sleep 2005;28:499-521.

7. Young T, Skatrud J. Peppard PE. Risk factors for obstructive sleep apnea in adults. JAMA 2004; 291:2013-6.

8. Schwartz AR, Gold AR, Schubert N, et al. Effect of weight loss on upper airway collapsibility in obstructive sleep apnea. Am Rev Respir Dis 1991;144:494-8.

9. Buchwald H, Avidor Y, Braunwald E, et al. Bariatric surgery: a systematic review and meta-analysis. JAMA 2004;292:1724-37.

10. Chung F, Yegneswaran B, Liao P, et al. STOP 
questionnaire: a tool to screen patients for obstructive sleep apnea. Anesthesiology 2008;108:812-21.

11. Gross JB, Bachenberg KL, Benumof JL, et al. Practice guidelines for the perioperative management of patients with obstructive sleep apnea: a report by the American Society of Anesthesiologists Task Force on Perioperative Management of patients with obstructive sleep apnea. Anesthesiology 2006;104:1081-93.

12. Danzi-Soares NJ, Genta PR, Nerbass FB, et al. Obstructive sleep apnea is common among patients referred for coronary artery bypass grafting and can be diagnosed by portable monitoring. Coron Artery Dis 2012;23:31-8.

13. van Oosten EM, Song W, Wang T, et al. The Effect of Obstructive Sleep Apnea on the Expression of Herg Potassium Ion Channels in Human Atrial Tissue: A Pilot Study. Canadian J Cardiol 2013;29:S106-7.

14. Lurie A. Endothelial dysfunction in adults with obstructive sleep apnea. Adv Cardiol 2011;46:139-70.

15. Peng Y, Yuan G, Overholt JL, et al. Systemic and cellular responses to intermittent hypoxia: evidence for oxidative stress and mitochondrial dysfunction. Adv Exp Med Biol 2003;536:559-64.

16. Albustami OM, Tribble RW, Sharma S, et al. Obstructive Sleep Apnea Risk Factors and Postoperative Complications in Patients Undergoing Elective Coronary Artery Bypass Graft Surgery. Chest J 2010;138:502A.

17. Chung F, Subramanyam R, Liao P, et al. High STOPBang score indicates a high probability of obstructive sleep apnoea, Br J Anaesth 2012;108:768-75.

18. Ahmad S, Nagle A, McCarthy RJ, et al. Postoperative hypoxemia in morbidly obese patients with and without

Cite this article as: Krishnasamy S, Sahid SM, Hashim SA, Singh S, Chung F, Mokhtar RA, Yin WC. Obstructive sleep apnoea and open heart surgery: a review of its incidence and impact to patients. J Thorac Dis 2019;11(12):5453-5462. doi: $10.21037 /$ jtd.2019.11.44 obstructive sleep apnea undergoing laparoscopic bariatric surgery. Anesth Analg 2008;107:138-43.

19. Kaw R, Golish J, Ghamande S, et al. Incremental risk of obstructive sleep apnea in cardiac surgical outcomes. J Cardiovasc Surg (Torino) 2006;47:683-9.

20. Finkel KJ, Searleman AC, Tymkew H. Prevalence of undiagnosed obstructive sleep apnea among adult surgical patients in an academic medical center. Sleep Med 2009;10:753-8.

21. Vasu TS, Doghramji K, Cavallazzi R, et al. Obstructive Sleep Apnea Syndrome and Postoperative Complications Clinical Use of the STOP-BANG Questionnaire. Arch Otolaryngol Head Neck Surg 2010;136:1020-4.

22. Erman MK, Stewart D, Einhorn D, et al. Validation of the ApneaLink for the screening of sleep apnea: a novel and simple single-channel recording device. J Clin Sleep Med 2007;3:387-92.

23. Lesser DJ, Haddad GG, Bush RA, et al. The utility of a portable recording device for screening of obstructive sleep apnea in obese adolescents. J Clin Sleep Med 2012;8:271-7.

24. de Oliveira ACT, Martinez D, Vasconcelos LFT, et al. Diagnosis of obstructive sleep apnea syndrome and its outcomes with home portable monitoring. Chest 2009;135:330-6.

25. Redline S, Yenokyan G, Gottlieb DJ, et al. Obstructive Sleep Apnea-Hypopnea and Incident Stroke The Sleep Heart Health Study. Am J Respir Crit Care Med 2010;182:269-77.

26. Flink BJ, Rivelli SK, Cox EA, et al. Obstructive sleep apnea and incidence of postoperative delirium after elective knee replacement in the nondemented elderly. Anesthesiology 2012;116:788-96. 